(EP-1062)

\title{
A nonspecific complaint such as diarrhea in elderly with hyperthyroidism: Evaluation with a case
}

\author{
Sefa Sarac ${ }^{1}$, Pelin Tütüncüoglu ${ }^{2}$, Sumru Savaş ${ }^{3}$, Fulden Sarac $^{3}$ \\ 1.Department of Cardiology, Katip Celebi University, Ataturk Training and Research Hospital / Izmir / \\ TURKEY \\ 2.Department of Endocrinology and Metabolism, Katip Celebi University, Ataturk Training and Research \\ Hospital / Izmir / TURKEY \\ 3.Department of Internal Medicine, Section of Geriatrics, Ege University Medical Faculty / Izmir / TURKEY
}

- Introduction: Hyperthyroidism in the elderly can present with subtle nonspecific complaints. Patients with long-standing goiter can develop autonomous nodules resulting in toxic nodular goiter.

- Case report: An 86 year old women was referred from gastroenterologist for thyroid disease because of low TSH. She had diarrhea with five to eight bowel movements a day for six months. She denied palpitations, heat intolerance or muscle weakness. She had been noted to have goiter at about age 45 years. Some times, she was treated with propyiltiouracil. There was a family history in her coisen. And also, she had hypertensive and statin treatments such as valsartan and simvastatin, respectively. After she had suffered from diarrhea, drugs related hypertension and hyperlipidemia were stopped. However, no change of characteristics of diarrhea were found.
- $\quad$ Physical examination revealed markedly enlarged to at least to times the normal size thyroid gland such as multinodular. The heart showed regular rhythm. Pulse was 76 and blood pressure was $130 / 60 \mathrm{mmHg}$. There were no thyroid eye sign.

Laboratory data that accomanied the patient included TSH of less than 0.01 mikroIU/ml (0.35- 5.5), FT4 of 2.1 $\mathrm{ng} / \mathrm{dl}(0.89-1.76)$, FT3 of $5.9 \mathrm{pg} / \mathrm{ml}$ (2.3-4.2). Thyroid nuclear scan showed irregular uptake with multiple hot nodules bilaterally. Ultrasound of thyroid showed a left sided hypoechoic nodules measuring $2 \mathrm{X} 3 \mathrm{~cm}$ and $1.1 \mathrm{X} 1$ $\mathrm{cm}$ with minimal peripheral vascularity. And also, $1 \mathrm{X} 1.5 \mathrm{~cm}$ solid and $1.3 \mathrm{X} 2 \mathrm{~cm}$ cystic nodules were shown at the right lobe .

- The diagnosis was toxic multinoduler goiter with subclinical hyperthyroidism. However, she was clinically hyperthyroidism and was treated with RAI. After 1 moths, she was euthyroide and had no diarrhea and any complaint. 